\title{
Knowledge Attitude and practice towards solid and liquid waste Management among Addis ketema and Kometa kebele community Mizan-Aman town, Bench - Maji zone, South Nations Nationalities and Peoples Regional State, South West Ethiopia, 2017
}

Yayehyirad Yemaneh ${ }^{1}$, Tesfaye Abera² ${ }^{2}$ Dejene Hailu², Wondewessen Niguse ${ }^{2}$, Lelisa Chewaka ${ }^{2}$, Tariku Daniel ${ }^{2}$, Hawi Abebe ${ }^{2}$, Nardos Tsegaye ${ }^{2}$

Yemaneh Y, Abera T, Hailu D, et al. Knowledge Attitude and practice towards solid and liquid waste Management among Addis ketema and Kometa kebele community Mizan-Aman town, Bench - Maji zone, South Nations Nationalities and Peoples Regional State, South West Ethiopia, 2017. J Environ Geol. 2017;1(1):17-21.

BACKGROUND: Waste is defined as unwanted remains, residues discarded, and material or by products which are no longer required by the initial user. These materials are by-products of human activities such as process of preparation, manufacture, packing, repacking, unpacking, construction, renovation of structures and mining operations. Almost any substance that is discarded is designated as waste, but it may also be considered as a potential resource

OBJECTIVES: The aim of this study was to assess the knowledge, attitude and practice of the community residing in Addis Ketema and Kometa kebele towards waste disposal management Mizan-Aman Town, Bench-Maji Zone, SNNPRS, South West Ethiopia, 2017.

METHODOLOGY: A community based descriptive cross-sectional study design was employed and systematic sampling technique was used to select the study participants. Data was collected from 392 selected samples in every
Kth interval which was 13 th, and Data quality was assured by performing pre-test to evaluate the appropriateness of data collection instrument and after collection of the data it was tallied manually, processed and analyzed in a line of its objective and frequency and percentage of the result were presented by using tables, graphs and charts.

RESULT: The finding of this study showed that majority $84 \%$ of the respondents were females, regarding their ethnicity $35.5 \%$ were Bench, also the majority of the participants $(87.1 \%)$ were married with regard to their religion (47\%) were Orthodox, on the other hand $48.6 \%$ of the respondents were the age between $21-30$. Furthermore, the study showed that $81.8 \%$ of the respondents have good knowledge, $77.5 \%$ of the participants showed positive attitudes toward waste management as well as $76.9 \%$ of participants have a good practice toward waste management.

CONCLUSION AND RECOMMENDATION: The finding of the study revealed that majority of Mizan-Aman town community has a good level of knowledge, have a positive attitude and showed good practice toward waste management.

Key Words: Solid waste, Liquid waste, Community

Improved sanitation attributes to $36 \%$ reduction in risk of diarrhea while hand washing with soap reduces the risk of diarrhea by $48 \%$ (10). In addition, good hygiene practices improve overall health through reduced rates of pneumonia, scabies, skin and eye infections, and influenza (11). Hand washing is also associated with lower respiratory infection (12). The seriousness of environmental depletion in Ethiopia witness as that the relationship between natural environmental and people are unfriendly. Thus it seems high time to take urgent actions by readdressing people's life style and experience sustainable development by acquiring appropriate environment knowledge, knowhow, skills and capacities (13).

\section{MATERIALS AND METHODS}

The management of waste should focus on how to find the value and redirect it back to the community. But unfortunately, our collecting and dumping the process mix and crush everything together; and make separation an expensive and sometimes impossible task to properly manage wastes (2).

The proper management of solid wastes generated from individual house, institutions such as hospitals, health centers; from public eating and drinking establishments (hotels, restaurants, etc.); from business and working places is a very important part of environmental health service in a community. If these wastes are not disposed in a proper way, they create breeding places for insects such as flies, mosquitoes etc.; they provide food and harborages for rats. These insects and rats are health risk in that they are potential disease transmitters. In addition to health problems rats also imposes an economic problem (3).

The seriousness of environmental depletion in Ethiopia reveals the relationship between natural environment and peoples are unfriendly. Thus it seems it will require high time to take urgent actions by modifying peoples life style, making people an experienced of sustainable development by acquiring appropriate environmental knowledge, knowhow, skills and capacities (35) millions more (4-9).

\section{Study area and period}

This study was conducted in Addis and Kometa kebele, Mizan-Aman town, Bench-Maji Zone, SNNPR, South West Ethiopia which is found about 568 $\mathrm{km}$ from the capital city Addis Ababa and $833 \mathrm{~km}$ from Awasa. According to Aman Town is 48,706 and the total number of household in Mizan-Aman town is 12,824 . The town is known for its diver's ethnicity. Among those Bench, Kefa and Amhara respectively accounts majority numbers. The town is a place for many governmental and private organizations/service providers to the community such as bank, telephone, post office, one University teaching hospital, one health center, one health science college, one university and there are some different levels of private clinic and pharmacy, also the town has $\mathrm{KG}$, elementary, high school, senior secondary and preparatory schools as well as one college of agriculture. So this study was conducted from April 26-May 07/2017 on two randomly selected Kebeles which were Addis Ketema and Kometa Kebele. the central statistical agency of Ethiopia 2008, the population size of Mizan-

${ }^{1}$ Department of Midwifery, College of Health Sciences, Mizan-Tepi University, Mizan-Teferi Ethiopia; ${ }^{2}$ Department of Nursing, College of Health Sciences, Mizan-Tepi University Mizan-Teferi Ethiopia.

Correspondence: Yayehyirad Yemaneh, Department of Midwifery, College of Health Sciences, Mizan-Tepi University, Mizan-Teferi Ethiopia. Telephone -+251912087869, e-mail buchiatuog@gmail.com

Received: September 19, 2017, Accepted: October 10, 2017, Published: October 17, 2017

OPEn ACCESS

This open-access article is distributed under the terms of the Creative Commons Attribution Non-Commercial License (CC BY-NC) (http:// creativecommons.org/licenses/by-nc/4.0/), which permits reuse, distribution and reproduction of the article, provided that the original work is properly cited and the reuse is restricted to noncommercial purposes. For commercial reuse, contact reprints@pulsus.com 


\section{Populations}

\section{Source population}

The source population of the study included all house hold in Addis and Kometa kebele.

\section{$\underline{\text { Study population }}$}

The study populations were selected house hold of Addis and Kometa kebele.

\section{Inclusion criteria}

All house hold members whose age was above 18 years and available during the study period.

\section{Exclusion criteria}

Populations who were excluded from this study were those who could not available in the study period, and those who are not households of Addis and Kometa kebele as well as those who has psychiatric problem.

\section{Sample size determination}

Sample size was determined by using single population Proportion formula and its basic assumptions. Since there was limited study done in the area, the estimated prevalence rate was assumed to be $50 \%$, confidence interval of $95 \%$, margin of error $5 \%$ the initial sample size becomes. $n=Z^{2} P q / d^{2}, n=$ $(1.96)^{2}(0.5)(0.5) /(0.05) 2=384$. Since the study population number is less than 10,000 and sample size/study population is greater than 0.05 the final sample size $(\mathrm{Nf})$ was calculate using the correction formula $(\mathrm{n} / 1+\mathrm{n} / \mathrm{N})$ and adding 10\% Non-response rate the Final Sample size becomes 392 and $\mathrm{K}$ the interval to select the study participant was calculated using the formula $\mathrm{N} /$ $\mathrm{Nf}=5259 / 392=13$. Pretest $10 \%=20$.

Where:

$\mathrm{ni}=$ Initial sample size $=384$.

$\mathrm{Nf}=$ Final Sample size $=392$.

$\mathrm{N}=$ Source Populations $=5295$.

$z=$ Reliability coefficient for the desired confidence interval (CI) of $95 \%$.

$\mathrm{P}=$ the proportion of population possessing the character of interest.

$\mathrm{q}=1-\mathrm{p}$ and $\mathrm{d}=$ degree of precision $=0.05$ (allowed probability of error).

\section{Sampling technique}

Out of five kebeles found in the town two kebeles were selected using simple random sampling(lottery) method and Systematic sampling technique was used to select households included in the study population. Then the first house was located by lottery method and the next house hold was selected every $\mathrm{K}^{\text {th }}$ interval which is every $13^{\text {th }}$ interval.

\section{Data collection methods and instruments}

Data was collected by interviewing Mizan-Aman Town community house hold leaders by using structured questionnaire and check list. The questionnaire was prepared in English and translated to Amharic language to ensure clarity. Then data collection task was accomplished by assigned and trained health professionals.

\section{Data quality assurance and management}

Before the actual data collection, pre- test was conducted on $5 \%$ of population else from study area (Hibret Keble) to evaluate the appropriateness of the data collection instruments. The returned questioners were checked for completeness, consistency, sensitivity and for provision of adequate information on daily bases by the supervisors and principal investigators. After collecting, the data was tallied manually, processed and analyzed in a line of its objective using suitable statistical tools by using manual tally and table of frequency.

\section{Ethical consideration}

Official letter of cooperation was written from Mizan-Tepi University, department of nursing to Mizan- Aman Town Municipality. Permission was obtained from municipality and the respondents were informed by the data collectors about the objective of study as well as confidentiality of their information. The right of the respondents to refuse answering for few or all of the questions was also respected.

\section{Dissemination of the result}

The final result was submitted to Mizan-Tepi University College of Health Science, department of Nursing and Mizan-Aman Municipality and the study kebeles to be used as a reference material.

\section{RESULTS}

Out of 392 participants expected to be included 388 give their response and included in the study which gives response rate of $99 \%$.

\section{Socio- demographic characteristics}

In this study, nearly half of the respondents $183(48.6 \%)$ were between 21 . 30 years. According to the finding majority of respondents $326(84 \%)$ were females and out of 388 respondents $185(47.9 \%)$ were orthodox, concerning the ethnicity of respondents only 138(35.5\%) were Bench.

Regarding the marital status of the respondent's majority 338(87.1\%) were married, 161(41.9\%) were merchants in their occupation, the finding of the study also revealed $102(26.3 \%)$ could only write and read as well as, out of 388 respondents majority $310(79.9 \%)$ did not know their monthly income (Figures 1 and 2 and Table 1).

\section{Knowledge of participants regarding solid and liquid west management}

The finding of this study showed that all respondents $388(100 \%)$ know what waste mean, but they describe waste in different ways; of these 303(78\%) out of 388 respondents define waste as useless materials or dirt. On the other hand, all respondent 388(100\%) already know, solid and liquid wastes unless managed well cause for the generation of different infectious disease but out of 388 respondents majority $196(50.5 \%)$ did not knew solid wastes can be recycled for further use. Over all the study revealed majority $(81.8 \%)$ of the respondents have good knowledge while the rest $18.2 \%$ have poor knowledge (Table 2).

Attitudes of the study participants regarding solid and liquid waste management

As described with Figure 3 here under, (77.5\%) of the study participants had positive attitude concerning liquid and solid waste disposal management. At the study period, all of the respondents $(100 \%)$ thought that proper waste management has health and economic importance. The finding of the study also showed that more than half of respondents 208(53.6\%) did not accept the idea about every person is responsible for collection and proper disposition of wastes. On the other hand, all respondents believe that liquid and solid wastes must be collected separately as well as majority respondents $(72.1 \%)$ believed that waste should be recycled for further use (Figure 4).

\section{Age}

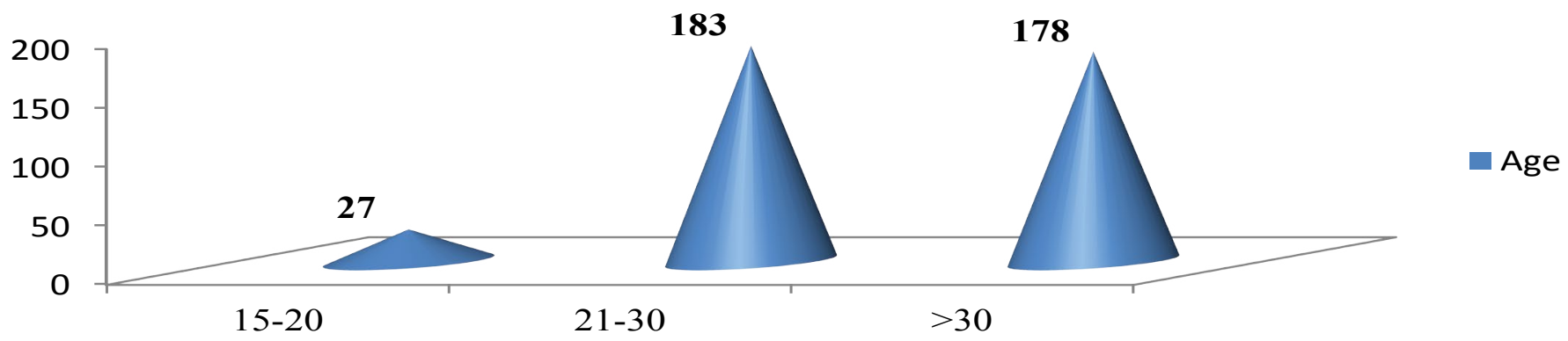

Figure 1) Showing of the study participants in Addis ketema and Kometa kebele, Mizan-Aman Town Bench-Maji Zone, SNNPRS South West Ethiopia 2017 


\section{Ethnicity}

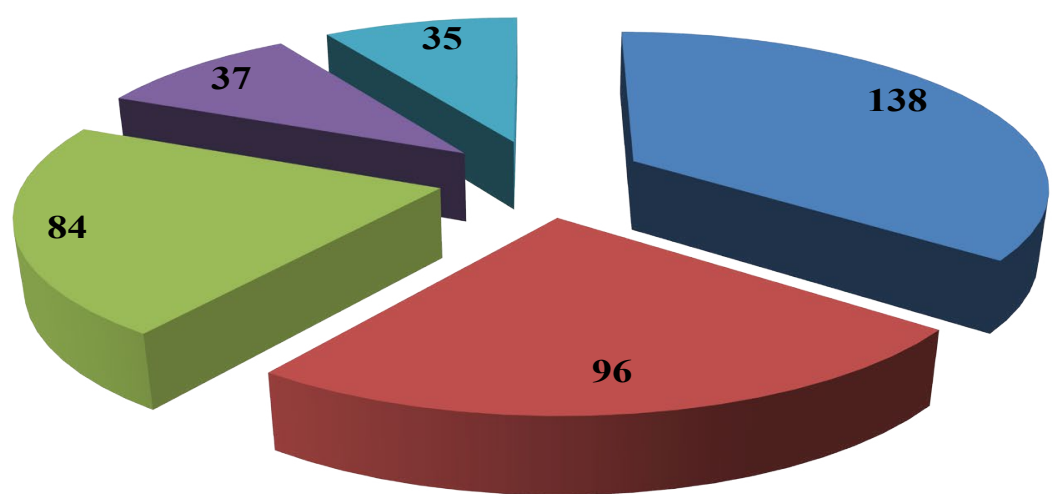

Bench

Kefa

Amhara

Oromo

Others

Figure 2) Showing the ethnic distribution of respondents, in Addis ketema and Kometa kebele, Mizan-Aman Town Bench-Maji Zone, SNNPRS South West, Ethiopia 2017

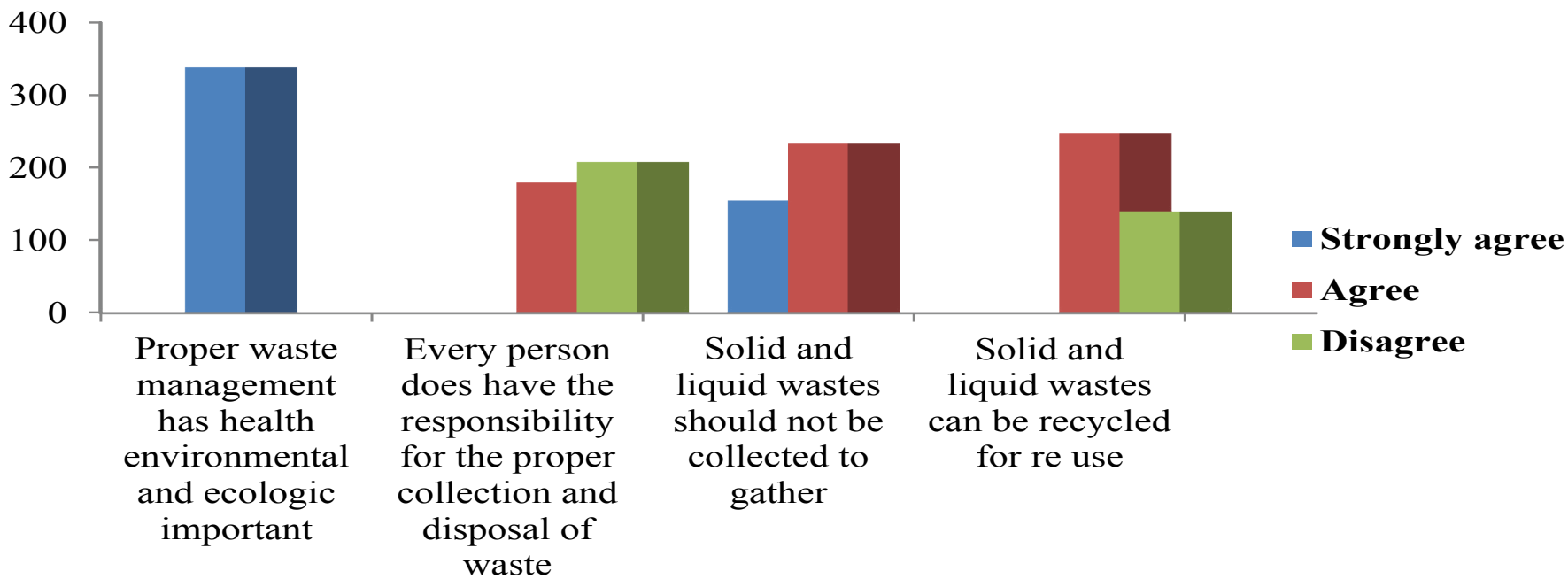

Figure 3) Showing Attitude towards solid and liquid waste management among communities residing in Addis ketema and Kometa kebele, Mizan-Aman Town BenchMaji Zone, SNNPRS South West Ethiopia 2017

TABLE 1

Showing the socio demographic characteristics of study participants in Addis ketema and Kometa kebele, Mizan-Aman Town Bench-Maji Zone, SNNPRS South West, Ethiopia 2017

\begin{tabular}{|c|c|c|c|}
\hline & Variables & Frequency & Percentage \\
\hline \multirow{2}{*}{ Sex } & Male & 62 & 16 \\
\hline & Female & 226 & 84 \\
\hline \multirow[t]{5}{*}{ Religion } & Muslims & 64 & 21.6 \\
\hline & Orthodox & 185 & 47.9 \\
\hline & Protestant & 120 & 25.5 \\
\hline & Catholic & 19 & 5 \\
\hline & Married & 338 & 87.1 \\
\hline \multirow[t]{4}{*}{ Marital status } & Single & 40 & 10.4 \\
\hline & Widowed & 10 & 2.6 \\
\hline & Illiterate & 82 & 21.2 \\
\hline & Read and write & 102 & 26.3 \\
\hline \multirow{4}{*}{ Educational status } & Elementary & 60 & 15.5 \\
\hline & High school & 74 & 18.6 \\
\hline & Diploma and above & 70 & 18 \\
\hline & Government employee & 71 & 18.3 \\
\hline \multirow[t]{2}{*}{ Occupational status } & Merchant & 163 & 41.9 \\
\hline & House wife & 154 & 39.6 \\
\hline \multirow{2}{*}{ thly income of respondents } & $>3500$ & 78 & 20.1 \\
\hline & Unknown & 310 & 79.9 \\
\hline
\end{tabular}


$\mathbf{8 1 . 1 0 \%}$

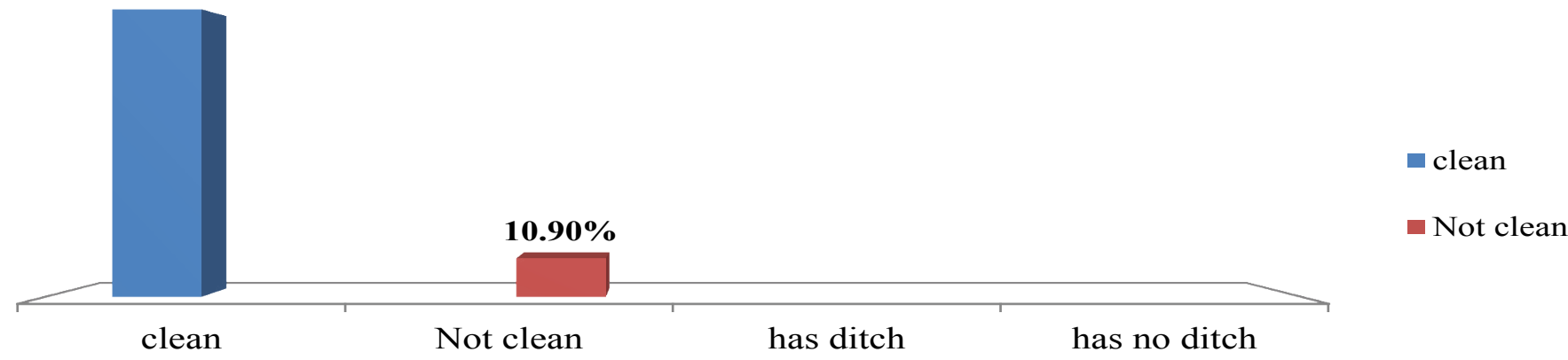

Figure 4) Showing the general conditions (cleanliness) of compounds of study participants

TABLE 2

Showing level of knowledge towards solid and liquid waste management among communities residing in Addis ketema and Kometa kebele, Mizan-Aman Town Bench-Maji Zone ,SNNPRS South West, Ethiopia 2017

Knowledge questions

1.Do you know what waste mean

2 If yes for question number 1 what is waste state

3 Do you know that if solid and liquid wastes are not managed well cause for generation of different infectious disease

4.Do you know that if solid wastes are properly managed they can be used for further other purpose

$\begin{array}{ccc}\text { Response } & \text { Frequency } & \text { Percentage } \\ \text { Yes } & 388 & 100 \\ \text { No } & 0 & 0 \\ \text { Useless materials } & 303 & 78 \\ \text { Sweepings from house } & 85 & 22 \\ \text { Yes } & 388 & 100 \\ \text { No } & 0 & 0 \\ \text { Yes } & 192 & 50.5 \\ \text { No } & 196 & 49.5\end{array}$

\section{TABLE 3}

Showing practice towards solid and liquid waste management among communities residing in Addis and Kometa kebele, MizanAman Town Bench-Maji Zone, SNNPRS South West Ethiopia 2017

Do you collect solid waste in your compound?

Do you manage solid and liquid waste after collection?

If yes for above question how do you manage solid wastes?
Practice questions

$\begin{array}{lcc}\text { Variables } & \text { Freq. } & \text { Percent } \\ \text { Yes } & 388 & 100 \\ \text { No } & 0 & 0 \\ \text { Yes } & 388 & 18 \\ \text { No } & 0 & 0 \\ \text { Burning } & 70 & 19.8 \\ \text { waste accumulation site } & 77 & 20.6 \\ \text { lecting in to the pit } & 80 & 13.7 \\ \text { with kebele administration } & 53 & 27.8 \\ \text { open dumping } & 108 & 30.9\end{array}$

The practices of the participants regarding solid and liquid west management

This study has revealed that $76.9 \%$ respondents show positive attitude while the rest 23.1 showed negative attitude. However, all study participants collect solid and liquid wastes in their compound on daily basis majority $(67.8 \%)$ of study population do not properly managed solid and liquid wastes after collection. Concerning the way of managing solid wastes, open dumping accounts for about (27.8\%) (Table 3$)$

\section{DISCUSSION}

Knowledge

Knowledge about a given issue has been recognized as one of the major determinants that shape the attitude, and practice of a community. A positive correlation between resident's level of knowledge about issues related to environment and their attitude has been supported by various literatures. Now a day's environmental problems in general and mishandling of wastes in particular are among the leading causes for ill-health and impediments for national development.

Improper waste management may have health and environmental hazards. Studies showed the relationship of many diseases to improper waste management. The finding of this study concerning the knowledge level of participants $81.8 \%$ of respondents have good, level of knowledge inconsistent with similar study conducted in Malaysia city that showed 64\% best knowledge level of respondents. (11)The reason for this discrepancy of the finding might be the difference of sample size or period of study or both and the socio-economic difference among the study participants.

Attitude

The finding also revealed that (77.5\%) study participants have positive attitude toward waste management nearly to other study which was conducted in Thailand city (92.2\%) (12). While quite different from similar study conducted in Malaysia city that revealed $65.9 \%$ of negative attitude of participant (11). The possible reason might be the period of study and place or age and sex of participants.

\section{Practice}

The finding of this study showed $76.9 \%$ of participants have good practices to ward waste management. Specifically, this study showed that $27.8 \%$ of respondents practices still open dumping of waste disposal this is inconsistent from similar study conducted in Gweru Zimbabwe that showed $65 \%$ practices of open dumping, the cause might be the presence of health extension workers and period of study (13). 


\section{CONCLUSION AND RECOMMENDATION}

\section{Conclusion}

The finding revealed that Addis Ketema and Kometa community have good level of knowledge as well as have positive attitude and have good practice to ward waste management

\section{Recommendation}

Based on the findings, the following recommendations were forwarded:

(i) To Mizan-Aman town municipality was recommended to prepare pits/ ditches in the town in sufficient quantity for solid waste disposal.

(ii) To Mizan-Aman town community has best knowledge, positive attitude and good practice so Mizan-Aman Municipality should do more to ensure the sustainability of this trend as well as to aware $100 \%$ of community.

(iii) To Researchers -Further detailed studies were recommended for intervention by using this high light for further interventions.

\section{AKNOWLEDEGEMENT}

We wish to express our gratitude to our Data collectors for their unreserved time and effort made.

Secondly, we are also grateful to Mizan-Tepi university collage of health science department of nursing for their grate contribution to us in conducting this research.

Finally, we are grateful to Mizan-Aman municipality for their provision of necessary information to us, as well as the study participants.

\section{CONFLICT OF INTEREST}

The authors declare that there is no any conflict of interest.

\section{REFERENCES}

1. http://www.unicef.org/wes/index.html.

2. Rabie T, Curtis V. Hand washing and risk of respiratory infections: a quantitative systematicreview. Tropical Medicine \& International Health 2006;11(3):258-67.
3. Federal Democratic Republic of Ethiopia Ministry of Health. Solid and liquid waste management extension package. 2004.

4. United Nations Development Programme (UNDP). Beyond scarcity: power, poverty and the global water crisis. Human Development Report. New York 2006:25-36.

5. Abebaw D. Determinants of solid waste disposal practices in urban areas of Ethiopia: A household Level Analysis. Eastern Africa Social Science Research Review 2008;24(1):1-14.

6. Tefera W. Technical issues of sanitation and hygiene in Mirab Abaya and Alaba: A case study report from the Southern Nations Region (SNNPR) of Ethiopia. RIPPLE Working Paper no.2. 2008.

7. Legesse W, Haile MD, Kloos H. Water supply and sanitation. In: Berhane Y, Haile Mariam D, Kloos H eds. Epidemiology and Ecology of health and disease in Ethiopia. Shama Books, 2006:129-146.

8. Unpublished data from census record of the Kersa Demographic Surveillance-Health Research Center, 2007.

9. World Health Organization. Combating water borne disease at the house hold level: International network to promote house hold water treatment and safe storage. Geneva, Switzerland. WHO, 1993.

10. Atlabachew G. Learners, academic staffs'. environmental knowledge, attitude, intension and behavior of Adama: Un published MA Thesis, School of Graduate Studies, Addis Ababa University, Addis Ababa 2007:15.

11. Chainarong A. Community mapping and theory of planned behavior as study tools for solid waste management. Journal of Waste Management 2014

12. Asmawati D, NorBa'yah A, Fatimah Y. Environmental awareness and education a key approach to solid waste management. A case study of University in Malaysia, Kualalampur 2012.

13. Steven J, Daniel T. Solid waste management practices in the informal sector of Gweru, Zimbabwe. Journal of Waste Management 2014. 